\title{
Total diz protezi sonrası periprostetik kırıklar
}

\section{Periprosthetic fractures following total knee arthroplasty}

\author{
Oğuz Şükrü Poyanlıํㄹ Emre Koraman ${ }^{2}$ \\ ${ }^{1}$ İstanbul Medeniyet Üniversitesi Göztepe Prof. Dr. Süleyman Yalçın Şehir Hastanesi, \\ Ortopedi ve Travmatoloji Kliniği, Kadıköy, İstanbul \\ ${ }^{2}$ Tuzla Devlet Hastanesi, Ortopedi ve Travmatoloji Kliniği, Tuzla, İstanbul
}

\begin{abstract}
Oldukça nadir görülmesine rağmen diz çevresi periprostetik kırıkları, tüm periprostetik kırıklar arasında en sık karşılaşılanıdır. Total diz protezi uygulamasının giderek artması, ameliyattan sonra aktivite artışı ve beklenen yaşam süresindeki artış ile birlikte periprostetik kırıklarla daha sık karşılaşılmaktadır. Bu kırıklar sıklığına göre sırasıyla femur, tibia ve patellada görülmektedir. Bu kırıkların tedavisinde amaçlar; kırığın kaynaması, diz hareketlerinin sağlanması ve ağrısız bir diz elde edilerek hastanın fonksiyonlarının korumasıdır. Cerrahi dışı tedavi seçenekleri uygun hastalarda tercih edilse de implant teknolojisindeki gelişmelerle cerrahi tedavide artış görülmektedir. Son yıllarda yapılan çalışmalarda artış görülse de bu kırıklar için belirlenmiş kesin bir tedavi algoritması bulunmamaktadır. Tedavideki yaklaşım cerrahın travma ve artroplasti ile ilgili bilgi ve tecrübesine dayanmaktadır. Cerrah, bu kırıkların yönetiminde kırık tipi, protezin durumu, kemik kalitesi, yumuşak dokunun durumu ve hastanın genel durumu gibi birçok etkeni göz önünde bulundurmalıdır. Bu derlemede, total diz protezi sonrası periprostetik kırıkların etiyolojisi, sınıflandırması ve güncel tedavi seçenekleri ile ilgili güncel bilgiler anlatılmaktadır.
\end{abstract}

Anahtar sözcükler: total diz protezi; periprostetik kırıklar; risk faktörleri; sınıflandırma; tedavi seçenekleri

\begin{abstract}
Although rarely seen, periprosthetic fracture around the knee is the most common among all periprosthetic fractures. Periprosthetic fractures are more common because of the increasing number of total knee replacement, postoperative activity level, and life expectancy. These fractures are seen in the femur, tibia and patella respectively, according to their frequency. The aim of treatment is union of fracture, maintenance of pre-fracture knee range of motion, and to obtaining a pain-free knee joint. Even though non-surgical treatment modalities are preferred in suitable patients, there is an increase in surgical treatment with advances in implant technology. On the other hand, no definite algorithm is present for treatment these fractures although increased studies recently in the literature. The treatment approach is based on the surgeon's knowledge and experience about trauma and arthroplasty. In the management of these fractures, the surgeon should consider many factors such as the type of fracture, the status of the prosthesis, bone quality, soft tissue and the general condition of the patient. In this review, current informations about the etiology, classification and treatment options of periprosthetic fractures after total knee arthroplasty is presented.
\end{abstract}

Key words: total knee arthroplasty; periprosthetic fractures; risk factors; classification; treatment modalities
$\mathbf{Y}$ aşam kalitesindeki ve beklenen yaşam süresindeki gelişmeler, total diz protezi (TDP) cerrahisi sıklığında ve dolayısıyla ameliyat sonrası komplikasyon olasılığında önemli artışlara neden olmuştur. ${ }^{[1]}$ Total diz protezi sonrası kırık riski oldukça yüksektir; çünkü TDP ameliyatı olan hastaların çoğu ileri yaşta ve osteopenik hastalardır. ${ }^{[2]}$ Diz çevresi periprostetik kırıkları, femur, tibia veya patellada eklem yüzeyinden 15 santimetre $(\mathrm{cm})$ veya kanal içi stemden $5 \mathrm{~cm}$ mesafe içindeki alanları etkileyen kırıklar olarak tanımlanmaktadır. ${ }^{[2]}$ Periprostetik diz kırıklarının en sık görüldüğü anatomik bölge femur olup, bunu sırasıyla tibia ve patella izlemektedir. ${ }^{[2]}$ Diğer kırıklara kıyasla periprostetik kırıklar, kırık tedavisi ve hasta iyileşmesi açısından oldukça zor kırıklardır. ${ }^{[1]} \mathrm{Bu}$ kırıklarda karşılaşılabilecek sorunlardan zayıf kemik stoğu, var olan implant ve çimento, kırık redüksiyonunu ve tespiti engelleyerek kaynamama ya da yanlış kaynamaya sebep olabilmektedir. ${ }^{[3]}$ Hastanın genel durumu ve ek hastalıkları da ameliyat sonrası iyileşme ve rehabilitasyon sürecini olumsuz etkilemektedir. Bununla birlikte uygun tespit materyallerinin ve cerrahi tekniklerin seçimi ile tatmin edici klinik sonuçlar elde edilebilir. ${ }^{[1]}$ Bu nedenle, periprostetik diz kırıklarının tedavisinde doğru tanı ve uygun müdahale büyük önem taşımaktadır.

iletişim / Contact: Prof. Dr. Oğuz Şükrü Poyanlı • E-posta / E-mail: opoyanli@gmail.com

ORCID iD: Oğuz Şükrü Poyanlı, 0000-0002-4126-0306 • Emre Koraman, 0000-0003-2715-2875

Geliş / Received: 12 Temmuz 2021 • Kabul / Accepted: 24 Temmuz 2021 


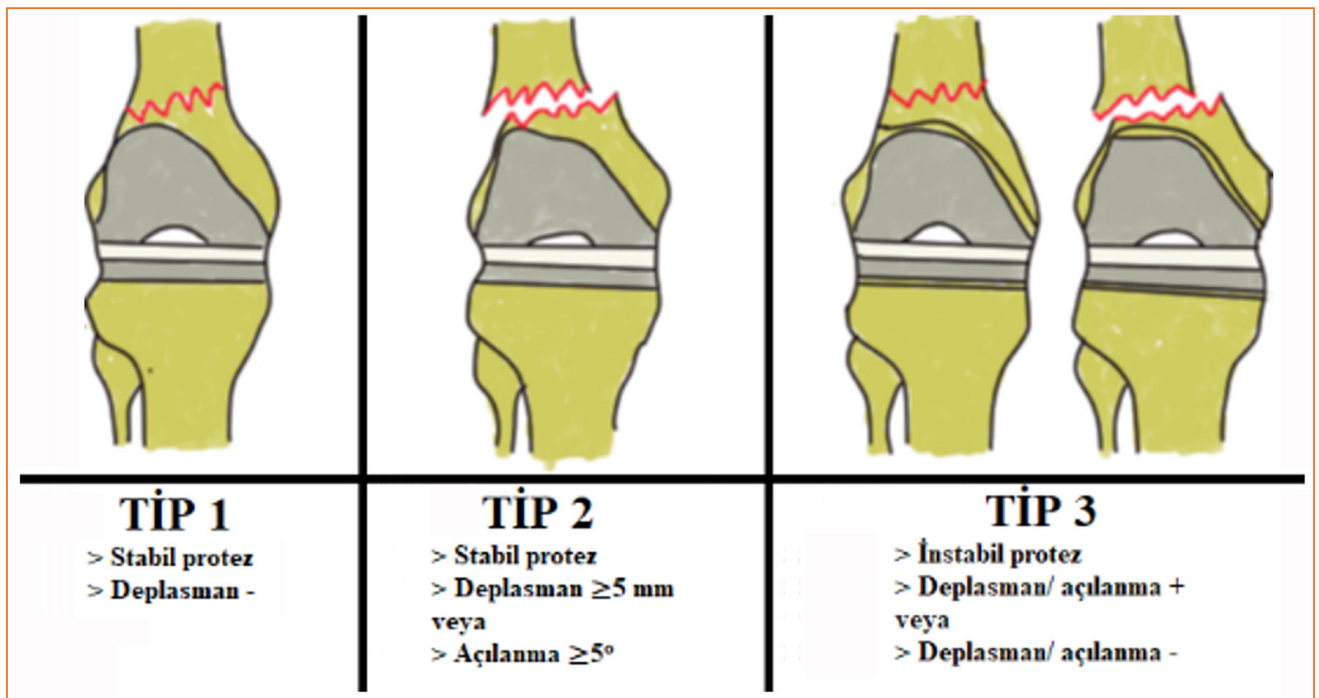

Şekil 1. Total diz protezi sonrası periprostetik femur kırığı Lewis ve Rorabeck sınıflaması.

\section{TOTAL DIZ PROTEZI SONRASI PERIPROSTETIK FEMUR KIRIKLARI}

Total diz protezi sonrası periprostetik kırıklar en sık femurda görülmekle birlikte femurda ise en sık suprakondiler bölge yerleşimlidir. ${ }^{[2]}$ Suprakondiler femur kırıkları TDP ameliyatlısı hastalarda 2-4 yıl içerisinde \%0,3-\%2,5 sıklıkta görülmektedir. ${ }^{[4]}$ Bu kırıklar genellikle torsiyonel veya kompresyon kuvvetlerinin olduğu düşük enerjili travmalardan sonra veya bazen yüksek enerjili travmalardan sonra meydana gelebilmektedir. ${ }^{[2]}$ Ameliyat esnasında femur anterior kortekste çentiklenme oluşması, metal implant ve femur korteksi arasında elastik modülus uyumsuzluğu, rotasyonel kısıtlayıı komponentlerin kullanılması, osteoliz, cerrahi alanda vasküler yapıların zarar görmesi sonucu kemiğin gecikmiş remodelizasyonu, diz ekleminde ankiloz, geçirilmiş revizyon ameliyatları, uzun süre steroid kullanımı, osteoporoz, romatoid artrit, ileri yaş, kadın cinsiyet ve nörolojik hastalıkların varlığı bu kırıklar için risk faktörleridir. ${ }^{[1,2]}$ Femur kırıkları aynı zamanda navigasyon-yardımlı TDP ameliyatları sonrası çivi (pin) deliklerinin olduğu alanlardan kırılarak da meydana gelebilir. ${ }^{[5]}$ Anterior femoral çentiklenme, çoğunlukla ameliyat sırasında femur anteriorunun aşırı kesilmesi sonucu femur anterior korteksinin zayıflaması durumudur. Bazı çalışmalarda anterior femoral çentiklenme ile periprostetik suprakondiler femur kırıkları arasında yakın bir ilişki olduğu gösterilmiştir (\%10-\%46). ${ }^{[6,7]}$ Culp ve ark.'nın yaptıkları çalışmada $3 \mathrm{~mm}$ 'lik anterior kortikal çentiklenmenin torsiyonel kuvvetlere karşı dayanıklılıkta \%30 azalmaya neden olduğu ve bunun da femur kırıkları için hazırlayıcı bir faktör olduğu bildirilmiştir. ${ }^{[6]}$ Ancak, yine de yapılan çalışmalarda anterior femoral çentiklenme ile periprostetik femur kırığı arasındaki ilişki çelişkilidir. ${ }^{[8]}$ Total diz protezi sonrası bir kırıktan şüpheleniliyorsa mutlaka femur iki yönlü grafileri çekilmelidir. Yapılan görüntülemelerde kırı̆ıın veya implant gevşemesinin kanıtları olmamasına rağmen hastada ağrı mevcudiyetinde ise enfeksiyonu dışlamak amacıyla kan tetkikleri ile enfeksiyon ilişkili değerler kontrol edilmeli, bunun yanı sıra mutlaka eklem aspirasyonu uygulanarak aspire edilen materyalden gerekli tetkikler çalışılmalıdır.

\section{Sinıflama}

Periprostetik femur kırıklarında tedavi stratejisini belirlemede önemli kriterlerden olan implant durumu ve kemik kalitesini göz önünde bulundurmaması sebebiyle geleneksel Neer sınıflamasının bazı kısıtlılıkları vardır. ${ }^{[9]} \mathrm{Bu}$ nedenle Lewis ve Rorabeck tarafından ortaya konulan sınıflama şu an birçok ortopedist tarafindan tercih edilmektedir. ${ }^{[9]}$ Lewis ve Rorabeck sınıflaması implant durumu ve kırık deplasmanı dikkate alınarak hazırlanmış bir sınıflandırmadır. ${ }^{\left[{ }^{[9]}\right.}$ Buna göre tip 1 kırıklar; deplasmanı olmayan ve implant tespitinin iyi olduğu kırıkları ifade etmektedir. Tip 2 kırıklar; $\geq 5 \mathrm{~mm}$ deplasman veya $\geq 5^{\circ}$ açılanmanın olduğu, fakat protezin stabil olduğu kırıklardır. Tip 2 kırıklar; tip $2 \mathrm{~A}$ ve tip $2 \mathrm{~B}$ kırıklar olarak iki alt gruba ayrılmaktadır ve tip 2B kırıklar parçalı kırıkları ifade etmektedir. Bu sınıflamaya göre tip 3 kırıklar ise kırığın deplasmanı veya açılanmasından bağımsız olarak protez komponentlerinin gevşemesi ve instabilitesini, polietilen aşınmasını tanımlamaktadır (Şekil 1). Su ve 
ark., femoral komponente göre kırık hattının yüksekliğini açıklayan bir sınıflandırma sistemi önermişlerdir: Tip 1 kırıklar femoral komponentin proksimalindedir; tip 2 kırıklar femoral komponentin proksimal ucundan başlayarak proksimale uzanır; tip 3 kırıklar ise femoral komponentin proksimal ucunun distalinde olan kırıklardır. ${ }^{[10]}$ Kim ve ark. tarafından ise kemik stoğu, protezin durumu ve kırığın durumu göz önüne alınarak bir sınıflandırma oluşturulmuştur. Tip 1 kırıklar, sağlam protez ve yeterli kemik stoğunun olduğu kırıklar olup, iki alt gruba ayrılmaktadır; tip 1A kırıklar konservatif tedaviye uygun iken tip 1B kırıklar cerrahi redüksiyon ve internal tespit gerektirmektedir. Tip 2 kırıklar, yeterli kemik stoğu ve redükte edilebilirliklerine rağmen protez instabilitesi ve/veya malpozisyonu nedeniyle revizyon artroplastisi ile tedavi gerektirmektedir. Tip 3 kırıklar ise çok parçalı ve kemik stoğunun az olduğu kırıklar olarak tanımlanmıştır. ${ }^{[11]}$

\section{Tedavi}

Periprostetik femur kırıklarında redüksiyon sonrası kabul edilebilirlik kriterleri; $<5 \mathrm{~mm}$ translasyon, $<5^{\circ}-$ $10^{\circ}$ açılanma, $<10^{\circ}$ rotasyonel deformite ve $<1 \mathrm{~cm}$ femoral kısalmadır. ${ }^{[12]}$ Çok parçalı kırıklarda, ciddi deplasman varlığında ve kırığın interkondiler alana uzanması durumlarında tedavi sonuçlarının tatmin edici olmaması kaçınılmazdır. ${ }^{[1]}$ Ayrıca, adduktor kaslar ve gastroknemius kasının distal fragmanı varus, fleksiyon ve iç rotasyon deformitesine getirmesi kaynamamaya sebep olabilir. ${ }^{[13]}$ Bu bilgiler doğrultusunda tedavi seçenekleri cerrahi dışı tedavi ve cerrahi tedavi olarak ikiye ayrılmaktadır.

\section{Cerrahi dışı tedavi}

Cerrahi dışı tedavi yöntemleri iskelet traksiyonu, alçı/atel uygulaması, breys kullanımı gibi seçenekleri içermektedir. İskelet traksiyonu çivi (pin) dibi enfeksiyonu, sinir palsisi, uzamış immobilizasyona bağlı bası yaraları, osteoporozda ilerleme ve diz ekleminde ankiloz gibi problemlere sebep olmasından dolayı güncel olarak çok fazla tercih edilmemektedir. Cerrahi dışı tedavi yöntemleri anestezi gerektirmemeleri, kanama ve/veya enfeksiyon riski barındırmamalarından dolayı avantajlıdır. Bu nedenle erken evre Rorabeck tip 1 kırıklarda tedavi seçeneği olarak değerlendirilebilir. Kırığın redüksiyonunun gerekli olduğu durumlarda redüksiyonu takiben 4-6 hafta immobilizasyon uygulanmalıdır. Bu sırada, kırık redüksiyonunun devamlılığının ve implant stabilitesinin gözlenmesi amacıyla iki haftalık aralıklarla hasta radyografik olarak izlenmelidir. Takiplerde uygun kaynama belirtileri görüldükten sonra alçı çıkarılarak menteşeli breys içerisinde aşamaIı eklem hareket açıklığı egzersizleri başlatılmalıdır. ${ }^{[1]}$ Takipler sırasında kırıkta deplasman meydana gelirse ya da implant stabilitesinden şüphe edilirse cerrahi kararı verilebilir. ${ }^{[2]}$ Chen ve ark., yaptıkları bir derlemede periprostetik femur kırıklarında cerrahi dışı ve cerrahi tedavilerin sonuçları karşılaştırılmıştır. Buna göre deplasmanı olmayan kırıklarda cerrahi dışı tedavinin başarı olasılığı \%83 bulunmuştur. Deplase kırıklarda ise cerrahi dışı tedavi uygulanan ve cerrahi tedavi uygulanan hastalarda memnuniyet oranlarında istatistiksel olarak anlamlı bir fark bulunamamıştır (\%61-\%67). Ek olarak, cerrahi uygulanan hasta gruplarında komplikasyon oranı daha yüksek tespit edilmiştir. ${ }^{[3]}$ Bununla birlikte, ciddi deplasmanı olan kırıklarda ve ileri derecede osteoporoz varlığında kırığın redüksiyonu ve redüksiyonun devamlılığının sürdürülmesi başarısız olabilir ve bu tip kırıklarda cerrahi dışı yöntemlerle takip yüksek yanlış kaynama olasılığına sahiptir. ${ }^{[2]}$ Moran ve ark., yaptıkları bir çalışmaya göre deplase periprostetik femur kırığı nedeniyle cerrahi dışı yöntemlerle tedavi edilen dokuz hastanın tamamında yanlış kaynama meydana gelirken, cerrahi tedavi uygulanan 15 hastanın 10'unda mükemmel sonuçlar elde edilmiştir. Bu nedenle, yüksek kaynamama ve yanlış kaynama riski göz önünde bulundurularak, Rorabeck tip 2 ve 3 kırıklarda cerrahi dışı tedavinin başarısı için uygun hasta seçimi şarttır. ${ }^{[14]}$

\section{Cerrahi tedavi}

Stabil olmayan, deplase kırıklarda cerrahi tedaviyle anatomik redüksiyon ve rijit tespit erken eklem hareket açıklığı egzersizlerine ve dolayısıyla hareket kabiliyetine olanak sağlamaktadır. ${ }^{[3,15]}$ Total diz protezi sonrası periprostetik femur kırıklarının tedavisinde eksternal fiksatör / Ilizarov, köprü plak, kondiler vida, retrograd intramedüller çivileme (iMÇ), kilitli plak ve revizyon TDP uygulamaları en sık kullanılan cerrahi yöntemlerdir. ${ }^{[1]}$

a) Plak osteosentez: $95^{\circ}$ açılı kamalı plaklar, dinamik kondiler vidalar, kondiler buttress plakları gibi internal tespit materyalleri zayıf kemik stoğuna sahip parçalı suprakondiler femur kırıklarında stabil tespit sağlamamaktadır ve femoral komponent veya çimento ile etkileşime neden olmaktadır. ${ }^{[2,9,12]}$ Kondiler buttress plakları varus çökmesine engel olamamaktadır. Kamalı plaklar ile dinamik kondiler vidalar da eklem çevresi periprostetik kırıklarda yeterli tespiti sağlamamaktadır. Bu nedenle, kemik grefti veya kemik çimentosu takviyesi kullanılarak osteopenik kemikte rijit tespiti sağlamak için araştırmalar yapılmıştır. Healy ve ark., yaptıkları bir çalışmada kamalı plaklar ve kondiler vidalı plakları kullanarak 20 tane Rorabeck tip 2 kırığı tedavi etmişler ve ek olarak şiddetli osteoporozu olan 15 dizde kemik grefti kullanmışlardır. İki dizde redüksiyon kaybına bağlı revizyon cerrahisi gerekmesine rağmen kırıkların tüm olgularda iyileştiği gözlenmiştir. ${ }^{[16]}$ 


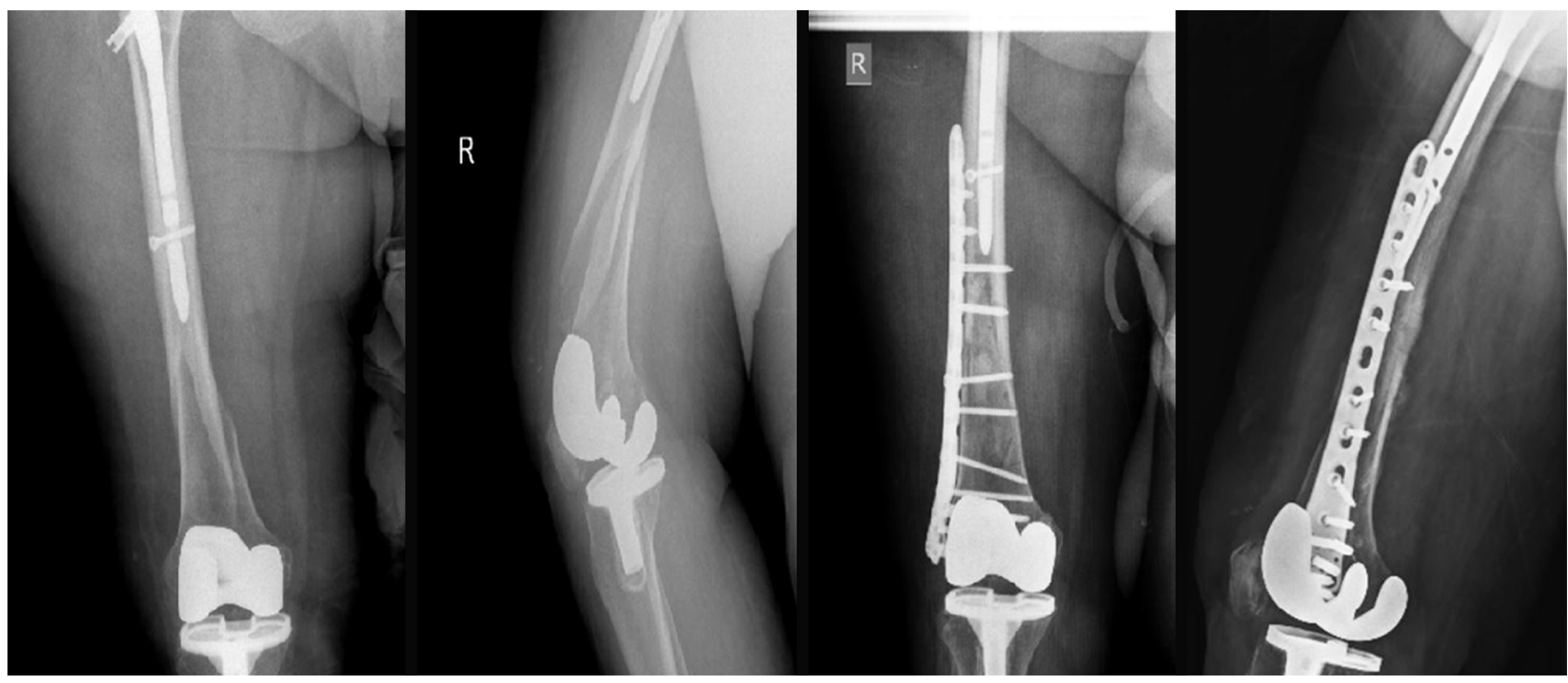

Şekil 2. Proksimal femur çivisi uygulanmış ve total diz protezi periprostetik femur kırığı gelişen bir hastada plak osteosentez uygulaması.

Mevcut kilitli plaklar ise sabit ve birçok açıda kilitlenme seçenekleri sayesinde eklem çevresi, çok parçalı ve osteoporotik kırıklarda geleneksel plaklara göre daha iyi tespit sağlamaktadır. ${ }^{[12,17]}$ Plak osteosentezinin dezavantajları arasında büyük insizyon ihtiyacı, yumuşak doku hasarı, kanama, periosta ve kan damarlarına verilen hasar nedeniyle kaynamama riskinin artması yer almaktadır. ${ }^{[1]}$ Son yıllarda ise daha az invaziv bir yöntemle tespit olanağı sağlayan kilitli plakların (less invasive stabilization system -LISS) kullanımı oldukça yaygınlaşmıştır (Şekil 2). LISS kavramı, ameliyat sırasında yumuşak doku ve periost hasarını, kanlanmanın bozulmasını en aza indirmektedir. Geleneksel tekniklere kıyasla kanama ve enfeksiyon gibi komplikasyon olasılığını en aza indirmekte ve hızlı kemik kaynamasını desteklemektedir. ${ }^{[12,18]}$ Kregor ve ark. yaptıkları çalışmada LISS uyguladıkları suprakondiler femur kırığı olan 38 dizden 36'sında herhangi bir komplikasyon olmaksızın kaynama gözlemlemişlerdir. [19]

b) Retrograd intramedüller çivi: Total diz protezi sonrası periprostetik femur kırıklarında tercih edilebilecek cerrahi yöntemlerden bir tanesi de retrograd intramedüller çivi (iMÇ) uygulamasıdır. ${ }^{[1]}$ Retrograd iMÇ uygulamasının geleneksel plak osteosentez uygulamasına göre daha az yumuşak doku hasarı ve kanamaya neden olması en önemli üstünlükleridir. Ayrıca periost kanlanmasının ve kırık hematomunun korunması sebebiyle de kırık kaynamasını olumlu yönde etkilemektedir. ${ }^{[1]}$ Ortopedik cerrahlar tarafından geçmişte kullanılan esnek intramedüller çiviler, deplase kırıklarda kompresyon ve torsiyonel kuvvetlere dayanaksız olması nedeniyle alt ekstremitede kısalığa ve rotasyon kusuruna neden olmaktadır ve günümüzde mümkün olduğunca tercih edilmemektedir. ${ }^{[2]}$ Günümüzde ise aksiyel yüklenme ve torsiyonel kuvvetlere karşı daha dayanıklı olan kilitli intramedüller çiviler tercih edilmektedir. ${ }^{[1]}$ Yapılan çalışmalarda Rorabeck tip 2 kırıklarda tercih edilen kilitli iMÇ'nin olgularda yüksek kaynama oranına sahip olduğu ve fonksiyonel sonuçların iyi olduğu bildirilmiştir.[20] Retrograd IMÇ uygulamasında önemli noktalardan biri çivi uzunluğunun küçük trokanter seviyesine kadar olması gerekliliğidir. Çivinin femurun istmusunu geçerek küçük trokanter seviyesine uzanması "araba sileceği etkisi"ni (windshield wiper effect) önlemekte ve stabiliteyi artırmaktadır. ${ }^{[21]}$ Ameliyat öncesi, femoral komponentin yerleşimi ve kullanılan protezin retrograd iMÇ uygulamasına uygun olup olmadığı mutlaka incelenmelidir. ${ }^{[1]}$ Total diz protezinde femoral komponentin hiperekstansiyonu oldukça sık görülen durumlardan birisi olup, IMÇ giriş yerinin olması gerekenden daha posteriorda yerleşmesine sebep olabilir. Ayrıca, kırık sonrası distal fragmanın koronal planda valgus dizilim bozukluğu sıklıkla karşılaşılan durumlardan biridir. Bu durumlardan kaçınmak için retrograd IMÇ uygulamalarında gerektiğinde blok vidalarının kullanılması önerilmektedir. ${ }^{[1]}$ Çivinin; patella, patellar tendon ya da eklem içine zarar vermemesi için yeteri kadar gömülmesi gerekliliği de uygulama esnasında dikkat edilmesi gereken durumlardan biridir. Retrograd IMÇ uygulamasında diz protezi femoral komponentinin çiviye uygunluğu, çivi çapının 

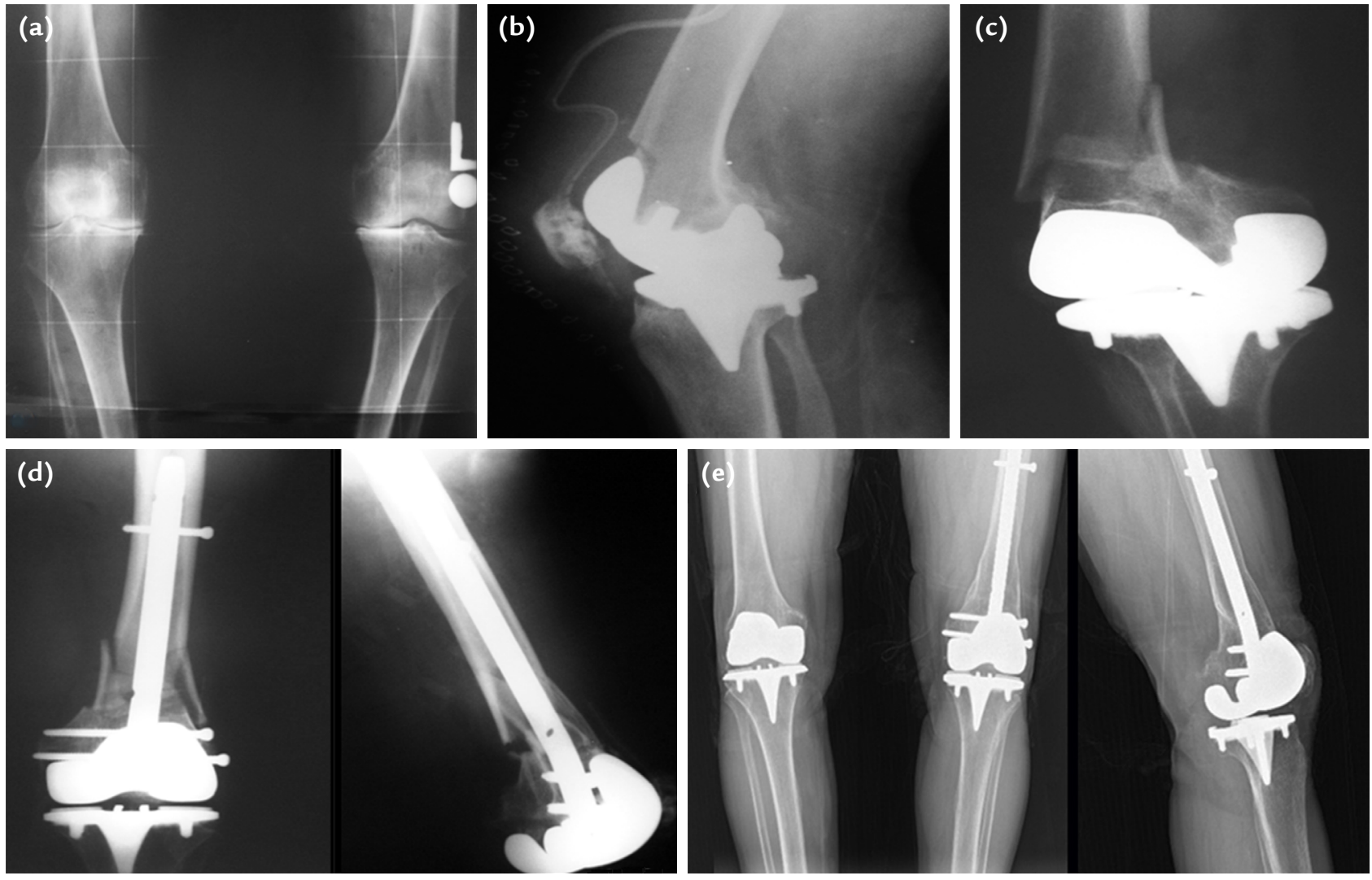

Şekil 3. a-e. Periprostetik femur kırığı sonrası retrograd iMÇ uygulaması: Total diz protezi (TDP) öncesi radyografi (a), TDP ameliyatı sonrası 1. gün radyografide femur anterior kortekste çentiklenme mevcut (b), TDP sonrası 3. yıl radyografide periprostetik femur kırığı (c), periprostetik femur kırığı için retrograd iMÇ uygulamasında ameliyat sonrası 1. gün ön-arka (AP) ve lateral radyografileri (d) ve periprostetik femur kırı̆ı retrograd iMÇ ameliyat sonrası 15. yıl ön-arka (AP) ve lateral radyografileri (e).

protezin açıkta bıraktığı giriş yeri (notch) çapına uygunluğu ve protezin yerleştirilmesinden sonra interkondiler notchun anteroposterior pozisyonu önemlidir. ${ }^{[22]}$ Bazı protezlerin çivinin giriş yerini kısıtlayıcı yapılarından dolayı retrograd IMÇ uygulamaya elverişli olmadığı görülmüştür. ${ }^{[22]}$ Maket kemiklerle yapılan bir çalışmada protez çivi giriş yerini kısıtlasa da çivi uygulamasının mümkün olduğu görülmüş; ancak canlı cerrahide çok ileri derecede fleksiyon yapılması zorunluluğundan dolayı bunun mümkün olmadığı ifade edilmektedir. ${ }^{[22]}$ Giriş yerinin olması gerekenden daha posteriorda olması da çivi uygulaması sırasında femur anterior kortekste kırığa sebep olabileceği gözlenmiştir. ${ }^{[22]}$ iMÇ’nin kontrendikasyonları arasında patella baja, IMÇ yerleştirilmesini engelleyen eklem ankilozu, $<11 \mathrm{~mm}$ interkondiler mesafe veya dar medüller kanal, total kalça atroplastisi sonrası veya proksimal femoral çivileme sonrası proksimal femurda intramedüller komponent varlı̆̆ı, çok parçalı veya çok distalde kırık varlığı bulunmaktadır (Şekil 3). ${ }^{[1,21]}$ c) Revizyon total diz artroplastisi: Deplasman veya kırık parça sayısına bakılmaksızın femoral komponentin stabilitesini bozan durumlarda revizyon TDP değerlendirilmesi gereken önemli seçeneklerden biridir. ${ }^{[1-3]}$ Komponent stabilitesi korunmuş olsa bile ekleme yakın çok parçalı tespit edilemeyecek kırıklar, diğer tedavilerde başarısızlık veya mevcut TDP'de dizilim bozukluğu olması durumlarında revizyon TDP uygun bir yaklaşımdır. ${ }^{[1-3]}$ Revizyon TDP'de uzun saplı femoral stem kullanılmalı ve stem kırık hattının proksimaline kadar uzanmalıdır.[1,2,13] Çoğunlukla çimentolu femoral komponent kullanılmasına rağmen kırık stabilitesini artırmak amacıyla uzun saplı steme strut (destek) allogreft ve serklaj telleri ile ek destek sağlanabilir. ${ }^{[1,13]}$ Kemik doku kaybının olduğu çok parçalı kırıklarda ve tespit sonrası kaynamama durumların$\mathrm{da}$, bacak uzunluğunun sağlanması ve en uygun diz eklem hareket açıklığı amaçlanarak tümör protezi ile distal femur replasmanını da kurtarıcı bir yöntem olarak akılda tutmak gerekmektedir. ${ }^{[1]}$ 


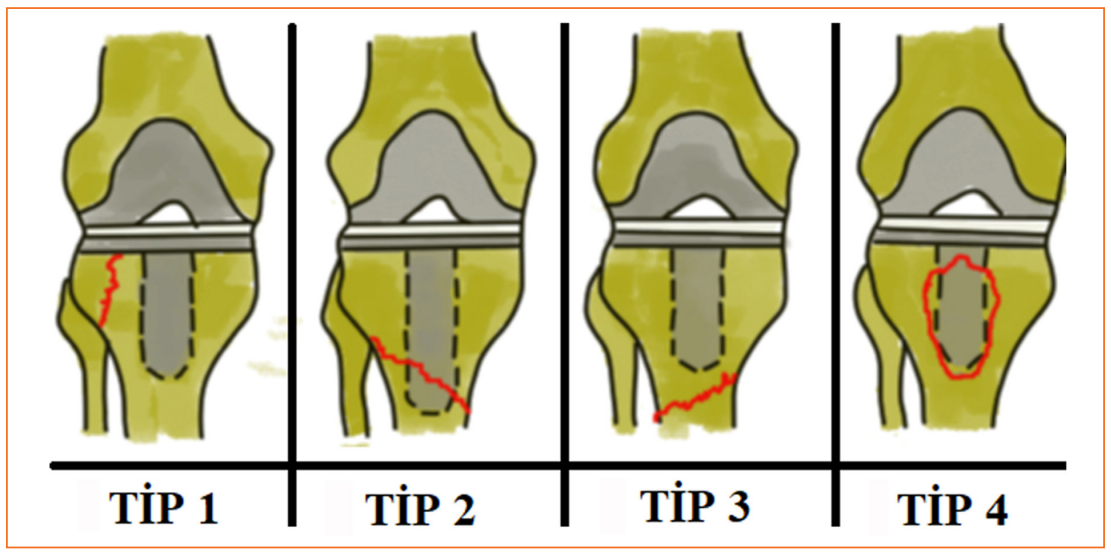

Şekil 4. Total diz protezi sonrası periprostetik tibia kırıkları Felix sınıflaması.

\section{TOTAL DIZ PROTEZI SONRASI PERIPROSTETIK TIBIAA KIRIKLARI}

Total diz protezi sonrası görülen periprostetik tibia kırıkları femura göre oldukça nadir görülmekte ve sıklığı \%0,4-\%1,7 arasındadır. ${ }^{[23]}$ Periprostetik tibia kırıkları; deneme tibial komponentin yerleştirilmesi, tibianın hazırlanması, çimentolama, komponent yerleştirilmesi, polietilen insert yerleştirilmesi ve revizyon cerrahisi uygulanırken mevcut komponentin çıkarılması gibi cerrahinin herhangi bir aşamasında meydana gelebileceği gibi cerrahi sonrasında da görülebilmektedir. ${ }^{[1]}$ Cerrahi sonrası görülen kırıklar çoğunlukla akut travma sonrası görülmekte olup, travma olmaksızın stres kırıkları da görülebilmektedir. ${ }^{[23]}$ Tibia kırıklarına sıklıkla komponent gevşemesi/instabilitesi, dizilim bozukluğu, eklem instabilitesi eşlik etmektedir. ${ }^{[2,23]}$ Rand ve Coventry, TDP'yi takiben tibia stres kırığı olan tüm hastalarda $(n=15)$ diz eklemi diziliminin bozuk olduğunu veya tibial komponentin yanlış yerleştirildiğini ortaya koymuşlardır. ${ }^{[2]}$ Ayrıca, tibial komponentin varusta yerleştirilmesi medial tibia plato kırıkları ile ilişkilendirilmiştir. ${ }^{[1]}$ Proksimal tibial osteotomi cerrahisi geçirmiş hastalarda ise tibial komponentin, kemiğin lateral korteksine zarar vermesine engel olmak için aşırı lateral yerleştirilmesinden kaçınılması tavsiye edilmektedir. ${ }^{[25]}$

\section{Sınıflama}

En sık kullanılan Felix sınıflamasına göre periprostetik tibia kırıkları dört gruba (tip 1-4) ve üç alt gruba (A, B, C) ayrılmaktadır (Şekil 4). Bu sınıflama sistemi kırı̆ın anatomik yerleşimi ve tibial komponentin durumu temel alınarak hazırlanmıştır. Tip 1 kırıklar tibial platoda yerleşimli, tip 2 kırıklar tibial platonun distalinde protezin stemine uzanan, tip 3 kırıklar stem distalinde yerleşimli, tip 4 kırıklar ise tibial tüberkülü içerisine alan kırıklardır. Alt gruplardan tip A kırıklar radyografik olarak komponentin stabil olduğu, tip B kırıklar radyografik olarak komponentin instabil olduğu, tip C kırıklar ise ameliyat esnasında görülen kırıklar olarak ifade edilmiştir. ${ }^{[23]}$

\section{Tedavi}

Periprostetik tibia kırıklarında tedavi kararı kırığın yerleşimine ve protezin durumuna göre verilmektedir. ${ }^{[1]}$ Tibial komponentin diziliminin normal olduğu, stabil olduğu ve kırıkta minör deplasmanın olduğu durumlarda gerekli ise kapalı redüksiyon ile birlikte alçı tedavisinin sonuçları memnun edici bulunmuştur. ${ }^{[23]}$ Bununla birlikte, kırıkta ciddi deplasman varlığında, instabil kırıklarda ve protezin stabil olmadığı durumlarda açık redüksiyon ve internal tespit ihtiyacı vardır. ${ }^{[1]}$ En sık kullanılan internal tespit yöntemi ise plak osteosentezdir. ${ }^{[23]}$ Kilitli plaklar zayıf kemik stoğunun olduğu olgularda bile sağlam tespit olanağı sağlamaktadır (Şekil 5). Cerrahi sırasında meydana gelen kırıklarda da tedavi kararı protezin durumu ve kırı̆ıın yerleşimine göre verilmektedir. Stabil olmayan tip 1C kırıklarda uzun saplı tibial komponent ile birlikte kırık parçaları arası vida tespiti tercih edilebilmektedir. Tip 2C kırıklar, uzun saplı tibial komponent ile kemik defekti olan alanlarda kemik grefti kullanılmaktadır. Tip 3C kırıklarda ise kırığın şekli ve yerine göre cerrahi ya da konservatif tedavi kararı verilmektedir. Tibial tüberkülü içeren kırıklar olan tip 4 kırıkların tedavisinde ekstansör mekanizmanın zarar görmemesine dikkat edilmelidir. ${ }^{[1]}$

Tibial komponent tasarımı gereği giriş deliğini kapattığından iMÇ uygulaması çok mümkün görünmese de TDP sonrası tibia cisim kırı̆̆ı gelişen olgularda IMÇ uygulanması için çeşitli teknikler olduğu çalışmalarda bildirilmiştir. ${ }^{[26,27]}$ 


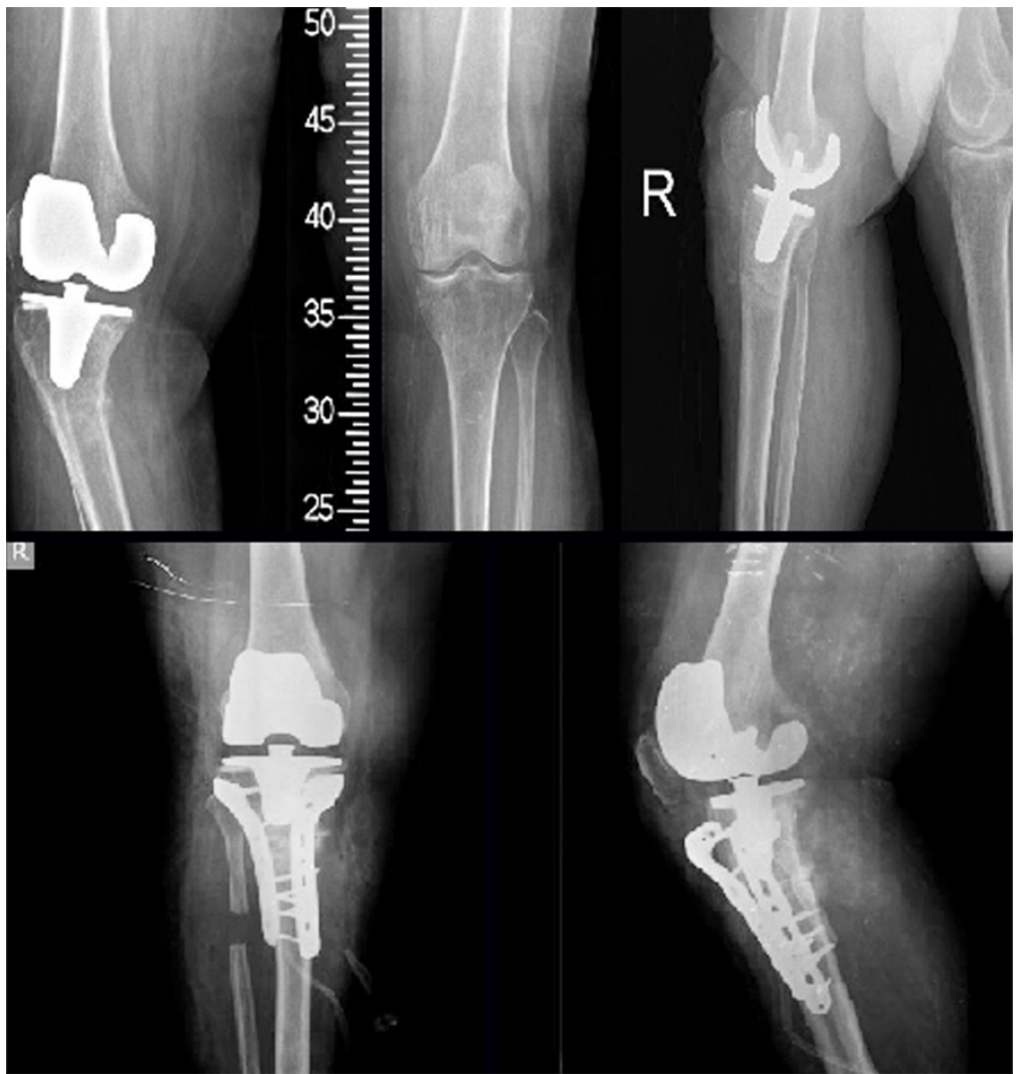

Şekil 5. Periprostetik tibia kırığı sonrası plak osteosentez uygulaması.
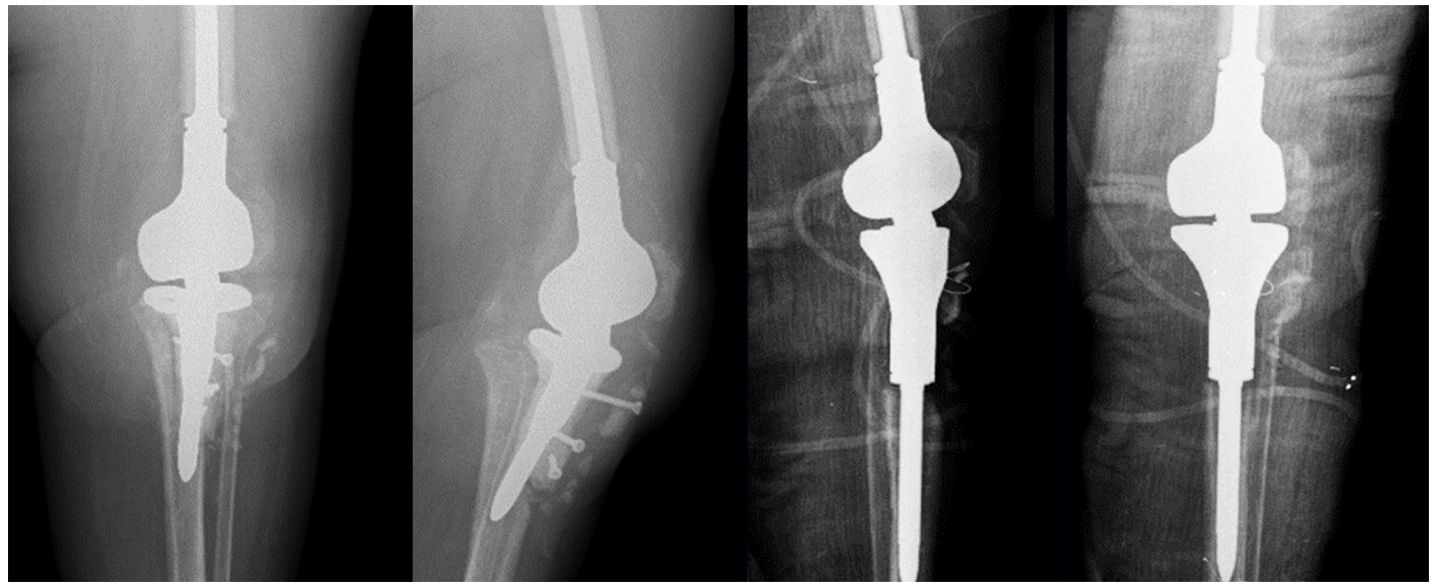

Şekil 6. Periprostetik tibia kırığı sonrası tümör rezeksiyon protezi uygulanan hastanın radyografik görüntüleri.

İnstabil tibial komponent varlığında revizyon TDP seçeneği akılda tutulmalıdır. ${ }^{[1,23]}$ Revizyon TDP kullanılacak tibial komponentin normal stemlere göre uzun saplı olması gerekmekte ve kırık hattını katederek distalde tutunmalı ya da fikse edilebilmelidir. Uzun saplı tibial komponent ile birlikte çok parçalı kırıklarda stabil olmayan kırık parçaların tespiti için ek internal tespit materyalleri kullanmak gerekebilir.
Kemik defektinin olduğu durumlarda komponent stabilitesini artırmak için metal bloklar kullanılabilmektedir. Metal blokların veya kalın polietilen insert kullanımı $5 \mathrm{~cm}$ veya daha az kemik defektinin olduğu durumlarda tedavide kullanılabilmektedir. Ancak, çok parçalı ve ciddi defektli kırıklar strut allogreft veya tümör protezi seçenekleri ile yönetilebilmektedir (Şekil 6). ${ }^{[28]}$ 


\section{TOTAL DIZ PROTEZI SONRASI PERIPROSTETIK PATELLA KIRIKLARI}

Periprostetik patella kırıkları oldukça nadir görülen bir durumdur. Görülme sıklığı patellar komponentin kullanıldığı durumlarda \%0,2-\%21 arasında, patellar komponentin kullanılmadığı durumlarda \%0,05 sıklıkta görülmektedir. ${ }^{[29]}$ Periprostetik patella kırıkları femur ve tibianın aksine erkeklerde kadınlara göre daha sık görülmektedir. Bu durumun kesin nedeni açılanamamakla birlikte daha yüksek aktivite düzeyi sebebiyle diz eklemine binen ağırlık ve ekstansiyon yükünün buna sebep olabileceği düşünülmektedir. ${ }^{[30]}$ Patella kırıkları genelde direkt travma sonucunda oluşmaktadır. ${ }^{[29]}$ Romatoid artrit, uzamış steroid kullanımı, patellar nekroz, alt ekstremitenin veya diz protezinin dizilim bozuklukları, arka çapraz bağ kesen protezlerin kullanımı ve bazı patellar protezler, cerrahi teknik hata gibi durumlar patella kırıklarının oluşmasını kolaylaştırıcı faktörlerdendir. ${ }^{[29,30]}$ Femoral komponentin yanlı̧̧ pozisyonda yerleştirilmesi tibiofemoral eklemde artan eksantrik yüke ve bu durum da en sonunda patella kırığı ile sonuçlanan patella subluksasyonuna sebep olmaktadır. ${ }^{[30]}$ Bunun yanı sıra, cerrahi esnasında patella etrafındaki yumuşak dokunun aşırı sıyrılması, lateral retinakular gevşetme esnasında lateral superior genikulat arterin yaralanması patellanın kanlanmasını bozmakta ve kırık ile sonuçlanabilen osteonekroza sebep olabilmektedir. ${ }^{[1,29,30]}$ Patellanın asimetrik rezeksiyonu, özellikle subkondral kemik veya lateral eklem yüzeyi rezeksiyona dâhil edildiğinde patella üzerindeki mekanik gerilimi artırmaktadır. ${ }^{[1]}$ Tersine, yetersiz rezeksiyon da patella-implant kalınlığının artmasına neden olarak patellofemoral ekleme daha fazla yük binmesine ve ekstansör mekanizmada aşırı traksiyona neden olmaktadır. ${ }^{[1,29,30]}$ Ek olarak, patellanın aşııı eversiyonu kırığa ve patellar tendon rüptürüne sebep olabilir. Bu nedenle; eversiyonun zor olduğu durumlarda öncesinde distal femoral kesiler yapılmalıdır. ${ }^{[25]}$ İmplant tasarımının da kırık riski üzerinde etkisi vardır: geniş, merkezi peg delikleri olan implantlar küçük periferik peg delikleri olanlara göre daha çok anterior patellar gerilmeye neden olur. Bu da artmış kırık riski ile sonuçlanmaktadır. ${ }^{[30]}$ Kırık için diğer kolaylaştırıcı faktörler, kemik çimentosu polimerizasyonunun ürettiği ısının neden olduğu osteonekroz ve $\geq 95^{\circ}$ tekrarlayan diz fleksiyonu sırasında oluşan kompresyon kuvvetleri olarak sıralanabilir. ${ }^{[29,30]}$ Periprostetik patella kırıklarından kaçınmak için bahsi geçen durumlardan engellenebilir olanlarla ilgili önlemler alınmalıdır.

\section{Sınıflama}

Goldberg ve ark., tanımladıkları sınıflama patella kırıklarını kırığın şekli, patellar komponentin stabilitesi, ekstansör mekanizmanın devamlılığı temel alınarak dört gruba ayırmaktadır. Goldberg tip 1 kırıklar patellanın periferinde bulunur ve patellar komponent ile ekstansör mekanizmayı etkilememektedir. Tip 2 kırıklarda implant-kemik bileşiminde veya ekstansör mekanizmada hasar mevcuttur. Tip 3 kırıklar patellanın inferior kutbunun kırıklarıdır. Bu kırıklar tip 3A (patellar tendon rüptürü eşlik eder) ve tip 3B (patellar tendon rüptürü eşlik etmez) olarak iki alt gruba ayrılmaktadır. Tip 4 kırıklar ise patellofemoral çıkıkların eşlik ettiği patella kırıklarını ifade etmektedir. ${ }^{[31]}$

\section{Tedavi}

Ekstansör mekanizmanın sağlam olması, patellar komponent instabilitesinin olmaması durumlarında cerrahi dışı tedavi bir tedavi seçeneği olarak düşünülebilir. ${ }^{[29,31]}$ Yapılan bir çalışmada hafif deplasmanı olan ve patellar komponentin stabil olduğu kırıklarda 38 dizden 37'sinde cerrahi dışı tedavi ile kemik kaynaması ve diz fonksiyonunun yeterli olduğu bildirilmiştir. ${ }^{[30]}$ Patellar komponentin stabil, ekstansör mekanizmanın hafif hasarlı olduğu kırıklarda internal tespit sonrası komplikasyon oranları \%50'ye kadar görülebilmektedir. ${ }^{[30]}$ Çok parçalı kırıkların tedavisinde bazı çalışmalar cerrahi dışı tedavi veya küçük kemik parçalarının eksizyonu ve patellar tendonun ya da kuadriseps femoris tendonunun kemiğe tespitini önermektedir. ${ }^{[2,30]}$ Patellar implant instabilitesinin olduğu durumlarda ise tedavi kararı geriye kalan kemik stoğun yeterliliğine göre verilmelidir. Yeterli kemik stoğu olan olgularda mevcut implantın çıkarılmasını takiben revizyon TDP ya da patellektomi yapılabilmektedir. Kemik stoğunun yeterli olmadığı durumlarda ise revizyon TDP yerine parsiyel ya da total patellektomi önerilmektedir. ${ }^{[1]}$ Bununla birlikte, patellar implantın instabil olduğu durumlarda cerrahi tedavinin yüksek komplikasyon oranlarına ilişkin bildiriler göz önüne alındığında, diz fonksiyonları iyi olan ve semptomları ileri düzeyde olmayan hastalarda ön planda cerrahi dışı tedaviler düşünülebilir. Bu tür hastaların çoğu ağrısız veya hafif ağrı ile seyreder ve patella kırıkları sıklıkla radyografilerde rastlantısal olarak tespit edilir ve 4-6 hafta süreyle alçı veya breys ile eklemin tespiti tatmin edici sonuçlar verebilmektedir. ${ }^{[2,30,31]}$

\section{SONUÇ}

Bu yaralanmaları yönetmenin amaçları ekstremitenin hizalanmasının ve uzunluğunun sağlanması, stabil tespit, destekleyici biyolojik çevrenin korunması ve erken eklem hareket açıklığının sağlanması olmalıdır. Bu amaçları yerine getirebilmek için üç ilkeyi temel alan bir değerlendirme yapmak gerekmektedir. ${ }^{[32]}$ ilk olarak, ortopedi ve travmatoloji uzmanı kırı̆̆ın yerini ve implant ile ilişkisini belirlemelidir. İkinci olarak, implantın durumu incelenmeli ve implant-kemik ara yüzünün stabil olup olmadığı, kırık öncesi ve kırık sonrası durumun 
Tablo 1. Yönetim stratejisinin açıklamasını içeren Birleşik Sınıflandırma Sistemi (The Unifıed Classification System $-U C S)^{[32]}$

\begin{tabular}{|c|c|c|}
\hline Tip & Tanım & Yönetim \\
\hline A (Apofizeal) & Kas/tendon yapışma yerinde & $\begin{array}{l}\text { Yumuşak dokunun durumu, deplasman } \\
\text { miktarı dikkate alınarak cerrahi / cerrahi dışı } \\
\text { tedavi }\end{array}$ \\
\hline B (Bed of the implant) & Protezin bulunduğu yeri (yatağını) içine & \\
\hline B1: Gevşememiş & alan kırıklar & B1: Redüksiyon ve tespit \\
\hline B2: Gevşeme var & & B2: Uzun saplı stem revizyon \\
\hline B3: Zayıf kemik kalitesi ve gevşeme var & & B3: Revizyon rekonstrüksiyon \\
\hline $\mathrm{C}$ (Clear of the implant bed) & $\begin{array}{l}\text { İmplantı içeren kemikte bulunan, ancak } \\
\text { implantın yatağından uzaktaki bir kırık }\end{array}$ & Redüksiyon ve tespit \\
\hline $\begin{array}{l}\text { D (Dividing one bone which supports two joint } \\
\text { replacements) }\end{array}$ & $\begin{array}{l}\text { İki farklı eklemin replasmanını takiben iki } \\
\text { eklemi de etkileyen kemik kırığı. Örneğin } \\
\text { kalça ve diz protezi ameliyatlısı bir } \\
\text { hastada femur kırığı }\end{array}$ & $\begin{array}{l}\text { “Engelleme” analizi. Radyografide kalça } \\
\text { veya dizi engelle kırığı kendi yararına göre } \\
\text { tedavi et }\end{array}$ \\
\hline $\begin{array}{l}\mathrm{E} \text { (Each of two bones supporting one joint } \\
\text { replacement) }\end{array}$ & $\begin{array}{l}\text { Tek eklem replasmanını etkileyen iki } \\
\text { kemiğin de kırığı. Örneğin, total diz } \\
\text { protezi sonrası femur ve tibia kırığı }\end{array}$ & Her kırığı kendi yararına uygun tedavi et \\
\hline F (Facing or articulating with an implant) & $\begin{array}{l}\text { Eklemle ilişkisi olan ama implant ile } \\
\text { yüzey değişikliği yapılmayan kemiklerin } \\
\text { kırığı. Örneğin, kalça hemiartroplastisi } \\
\text { sonrası asetabulum ya da patellar yüzeyin } \\
\text { değiştirilmediği TDP sonrası patella kırığı }\end{array}$ & \\
\hline
\end{tabular}

tespiti yapılmalıdır. Son olarak kemik stoğunun yeterliliği ve implantı destekleyen güç dikkate alınarak ek büyük rekonstrüksiyon prosedürlerine gerek kalmadan kırık tespiti veya revizyonun yapılıp yapılamayacağı belirlenmelidir. Bununla ilgili olarak birleştirilmiş bir sınıflandırma sistemi ve yönetim stratejilerini içeren bir algoritma oluşturulmuştur (Tablo 1). ${ }^{[32]}$

Bu kırıklar zorlu yaralanmalardır. Cerrah bu kırıklarda çoğunlukla riskli, ileri yaşta, sınırlı biyolojik ve fizyolojik rezervi bulunan hastalarla karşı karşıyadır. Amaç, her zaman hastanın erken hareket kabiliyetine kavuşması olmalıdır. Sonuçları optimize etmek için bu karmaşık yaralanmaların yönetimine özel ilgi duyan merkezlerin ve cerrahların belirlenmesine ihtiyaç vardır.

\section{KAYNAKLAR}

1. Yoo JD, Kim NK. Periprosthetic fractures following total knee arthroplasty. Knee Surg Releated Res 2015;27(1):1-9. Crossref

2. Dennis DA. Periprosthetic fractures following total knee arthroplasty. Instr Course Lect 2001;50:379-89. https:// pubmed.ncbi.nlm.nih.gov/11372337/

3. Chen F, Mont MA, Bachner RS. Management of ipsilateral supracondylar femur fractures following total knee arthroplasty. J Arthroplasty 1994;9(5):521-6. Crossref
4. Rorabeck $\mathrm{CH}$, Taylor JW. Periprosthetic fractures of the femur complicating total knee arthroplasty. Orthop Clin North Am 1999;30(2):265-77. Crossref

5. Li C-H, Chen T-H, Su Y-P, Shao P-C, Lee K-S, Chen W-M. Periprosthetic femoral supracondylar fracture after total knee arthroplasty with navigation system. J Arthroplasty 2008;23(2):304-7. Crossref

6. Culp RW, Schmidt RG, Hanks G, Mak A, Esterhai JL, Heppenstall RB. Supracondylar fracture of the femur following prosthetic knee arthroplasty. Clin Orthop Relat Res 1987;(222):212-22. Crossref

7. Ritter MA, Faris PM, Keating EM. Anterior femoral notching and ipsilateral supracondylar femur fracture in total knee arthroplasty. J Arthroplasty 1988;3(2):185-7. Crossref

8. Canton G, Ratti C, Fattori R, Hoxhaj B, Murena L. Periprosthetic knee fractures. A review of epidemiology, risk factors, diagnosis, management and outcome. Acta Biomed 2017;88(Suppl 2):11828. https://www.researchgate. net/publication/320868611_ Periprosthetic_knee_fractures_A_review_of_epidemiology_risk_ factors_diagnosis_management_and_outcome

9. Rorabeck $\mathrm{CH}$, Taylor JW. Classification of periprosthetic fractures complicating total knee arthroplasty. Orthop Clin North Am 1999;30(2):209-14. Crossref

10. Su ET, DeWal H, Di Cesare PE. Periprosthetic femoral fractures above total knee replacements. J Am Acad Orthop Surg 2004;12(1):12-20. Crossref

11. Kim K-I, Egol KA, Hozack WJ, Parvizi J. Periprosthetic fractures after total knee arthroplasties. Clin Orthop Relat Res 2006;446:167-75. Crossref 
12. DiGioia AM 3rd, Rubash HE. Periprosthetic fractures of the femur after total knee arthroplasty. A literature review and treatment algorithm. Clin Orthop Relat Res 1991;(271):13542. Crossref

13. Figgie MP, Goldberg VM, Figgie HE 3rd, Sobel M. The results of treatment of supracondylar fracture above total knee arthroplasty. J Arthroplasty 1990;5(3):267-76. Crossref

14. Moran MC, Brick GW, Sledge CB, Dysart SH, Chien EP. Supracondylar femoral fracture following total knee arthroplasty. Clin Orthop Relat Res 1996;324:196-209. Crossref

15. Redler LH, Dennis ER. Treatment of Adhesive Capsulitis of the Shoulder. J Am Acad Orthop Surg 2019;27(12):e544-54. Crossref

16. Healy WL, Siliski JM, Incavo SJ. Operative treatment of distal femoral fractures proximal to total knee replacements. J Bone Joint Surg Am 1993;75(1):27-34. Crossref

17. Frigg R, Appenzeller A, Christensen R, Frenk A, Gilbert S, Schavan R. The development of the distal femur Less Invasive Stabilization System (LISS). Injury 2001;32(Suppl 3):24-31. Crossref

18. Zlowodzki M, Williamson S, Cole PA, Zardiackas LD, Kregor PJ. Biomechanical evaluation of the less invasive stabilization system, angled blade plate, and retrograde intramedullary nail for the internal fixation of distal femur fractures. J Orthop Trauma 2004;18(8):494-502. Crossref

19. Kregor PJ, Hughes JL, Cole PA. Fixation of distal femoral fractures above total knee arthroplasty utilizing the Less Invasive Stabilization System (L.I.S.S.). Injury 2001;32(Suppl 3):64-75. Crossref

20. Murrell GA, Nunley JA. Interlocked supracondylar intramedullary nails for supracondylar fractures after total knee arthroplasty. A new treatment method. J Arthroplasty 1995;10(1):37-42. Crossref

21. Lee S-S, Lim S-J, Moon Y-W, Seo J-G. Outcomes of long retrograde intramedullary nailing for periprosthetic supracondylar femoral fractures following total knee arthroplasty. Arch Orthop Trauma Surg 2014;134(1):47-52. Crossref
22. Jones MD, Carpenter C, Mitchell SR, Whitehouse M, Mehendale S. Retrograde femoral nailing of periprosthetic fractures around total knee replacements. Injury 2016;47(2):460-4. Crossref

23. Felix NA, Stuart MJ, Hanssen AD. Periprosthetic fractures of the tibia associated with total knee arthroplasty. Clin Orthop Relat Res 1997;345:113-24. Crossref

24. Rand JA, Coventry MB. Stress fractures after total knee arthroplasty. J Bone Joint Surg Am 1980;62(2):226-33. Crossref

25. Backstein D, Safir O, Gross A. Periprosthetic fractures of the knee. J Arthroplasty 2007;22(4 Suppl):45-9. Crossref

26. Haller JM, Kubiak EN, Spiguel A, Gardner MJ, Horwitz DS. Intramedullary nailing of tibial shaft fractures distal to total knee arthroplasty. J Orthop Trauma 2014;28(12):e296-300. Crossref

27. Zafra-Jiménez JA, Pretell-Mazzini J, Resines-Erasun C. Distal tibial fracture below a total knee arthroplasty: retrograde intramedullary nailing as an alternative method of treatment: a case report. J Orthop Trauma 2011;25(7):e74-6. Crossref

28. Hanssen AD, Stuart MJ. Treatment of periprosthetic tibial fractures. Clin Orthop Relat Res 2000;380:91-8. Crossref

29. Windsor RE, Scuderi GR, Insall JN. Patellar fractures in total knee arthroplasty. J Arthroplasty 1989;4(Suppl):S63-7. Crossref

30. Ortiguera CJ, Berry DJ. Patellar fracture after total knee arthroplasty. J Bone Joint Surg Am 2002;84(4):532-40. Crossref

31. Goldberg VM, Figgie HE 3rd, Inglis AE, Figgie MP, Sobel $M$, Kelly M, Way M. Patellar fracture type and prognosis in condylar total knee arthroplasty. Clin Orthop Relat Res 1988;(236):115-22. Crossref

32. Duncan CP, Haddad FS. The Unified Classification System (UCS): improving our understanding of periprosthetic fractures. Bone Joint J 2014;96-B(6):713-6. Crossref 